University for Business and Technology in Kosovo

UBT Knowledge Center

UBT International Conference

2017 UBT International Conference

Oct 27th, 4:45 PM - 6:15 PM

\title{
Evaluation of physical - chemical contaminants in Lumbardhi River in Prizren for the period May - June 2017
}

\author{
Gashi Sami \\ University for Business and Technology, sami.gashi@outlook.com \\ Bajmaku Ymerr \\ Gymnasiums “Gjon Buzuku”, Prizren, ymerbajmaku@hotmail.com \\ Besar Veseli \\ University for Business and Technology, besa.veseli@ubt-uni.net \\ Drini Petrit \\ Factory of Zinc Galvanism, Prizren, petritdrini@yahoo.com
}

Follow this and additional works at: https://knowledgecenter.ubt-uni.net/conference

Part of the Bioresource and Agricultural Engineering Commons

\section{Recommended Citation}

Sami, Gashi; Ymerr, Bajmaku; Veseli, Besar; and Petrit, Drini, "Evaluation of physical - chemical contaminants in Lumbardhi River in Prizren for the period May - June 2017" (2017). UBT International Conference. 139.

https://knowledgecenter.ubt-uni.net/conference/2017/all-events/139

This Event is brought to you for free and open access by the Publication and Journals at UBT Knowledge Center. It has been accepted for inclusion in UBT International Conference by an authorized administrator of UBT Knowledge Center. For more information, please contact knowledge.center@ubt-uni.net. 


\title{
Evaluation of physical - chemical contaminants in Lumbardhi River in Prizren for the period May - June 2017
}

\author{
Gashi Sami ${ }^{1}$, Bajmaku Ymerr ${ }^{2}$, Besa Veseli ${ }^{3}$ Drini Petrit $^{4}$ \\ ${ }^{1}$ UBT - Higher Education Institution, Lagjja Kalabria, 10000 p.n., Prishtine, \\ Kosovo \\ sami.gashi@outlook.com \\ 2 Gymnasiums “Gjon Buzuku”, Prizren, \\ e-mail:ymerbajmaku@hotmail.com \\ ${ }^{3}$ UBT - Higher Education Institution, Lagjja Kalabria, 10000 p.n., Prishtine, Kosovo \\ besa.veseli@ubt-uni.net \\ ${ }^{4}$ Factory of Zinc Galvanism, Prizren, \\ E-mail: petritdrini@yahoo.com
}

\begin{abstract}
This paper covers the monitoring of water pollution in the river basin from the source to the White Drin flow monitoring the river flow both in the rural and urban areas of water quality. The biggest problem in environmental protection is the quality of surface water. The results from the analysis of the study will serve to know the pollution from these physical-chemical parameters and at the same time to manage the eco-status in order to prevent negative trends and create a desirable balancing of so important the ecosystem as it is the system consist of Lumbardhi River, with biodiversity still maintained. The purpose of the work is to know the pollution of the Lumbardhi River during the period May-June 2017 as we think during that period of time there is a larger water flow due to the atmospheric rainfall and melting of the snowfall from the mountains because the river source is from an altitude of over 2500 meters and has an extension of $37 \mathrm{~km}$ to its discharge into the next river. On the other hand, based on the ecological condition and the physicochemical characteristics of the Lumbardhi River during time intervals, will serve as a starting point for integrating them into the management plans and if necessary for the programs, measures and environmental protection activities that should be undertaken to prevent our river pollution as we are dealing with a river that runs through the middle of our city and if clean, it would increase the beauty of our city with its landscape. So, the samples for analysis have been taken in four sample locations with different distances that are marked with L1, L2, L3, L4 and the same ones will be presented in our fig. The analyses are done at the hydro meteorological institute of Kosovo Pristina.
\end{abstract}

Keywords: Dissolved Suspensive Substances (DSS), Biochemical Oxygen Demand/Consumption (BODs), and Chemical Oxygen Demand (COD), Total Organic Carbon (TOC). 


\section{Introduction}

The Lumbardhi River flows in the Sharr Mountains and overflows into the White Drin. It runs through the middle of the city of Prizren. There are discharges of Rural and Urban waters onto it, without any prior treatment. They are today the largest pollutant of water resources. Urban discharge waters originate from the production process and include: water from processes, sanitation waters and water from the purification of special equipment for each industry. Unlike municipal wastewater, whose composition is well known, the discharge waters from various industries and laundries, it is difficult to distinguish the great diversity of pollutants and their specific ingredients.

Based on the laboratory analysis, the state of the Lumbardhi River ecosystem was assessed by polluters for the period May-June 2017.

The purpose of water quality control of Lumbardhi River is to determine the water quality at higher and medium or low flow rates, in particular the dynamics of change during the arrival of the runoff (melting snow, heavy rain, etc.). Based on this and the fact that water quality is an essential element for calculating the balance of physical - chemical parameters, water quality measurements in these specific conditions are a very necessary engagement. This is particularly important in the Lumbardhi River areas where discharges occur because dispersed pollution has a great impact on water quality and the environment.

\section{Material and methods}

Analysis of the physical and chemical parameters has been done at the Hydro Meteorological Institute in Prishtina, in order to evaluate the realistic situation of the Lumbardh River. Researches have been conducted in four sample areas: the source of Lumbardhi - Prevalla (L1); Sredska (L2), City Park (L3) and Vlashnje (L4). During the study, we have dealt with all the flow of the Lumbardhi River from its source to its meeting with the River Drini i Bardhe (White Drin). We think that measures have been taken recently, it is increased the efficiency of municipal institutions for treatment of wastewater, industrial and other recipients for our river to be cleaner. Water flow as an element of special importance varies from season to season. This also causes contaminants to change during the seasons of the year. The following physicochemical parameters have been defined: DSS (Dissolved Suspensive Substances, COD (Chemical Oxygen Demand), BOD 5 (Biochemical Oxygen Demand) and TOC (Total Organic Carbon). Lumbardhi is studied in conditions where we think that water feeds are larger. The data are collected and recorded according to the standardized methodologies, which are reflected in the tables and following diagrams of this paper.

\section{Sample}

Sampling took place in time intervals May-June 2017, at four locations. Taking the water samples for laboratory analysis is done according to the recognized standards. This paper deals with the sampling of the Lumbardhi River of Prizren and Rural and Urban waters discharge, always respecting the standard methods and based on ISO 5667-5 of 2006, on standard sampling rules. 
In this way, we have tried to avoid the possibility of contamination of water samples for study. Sampling points for monitoring the dynamics of Lumbardhi's pollution are shown in Figure 1.

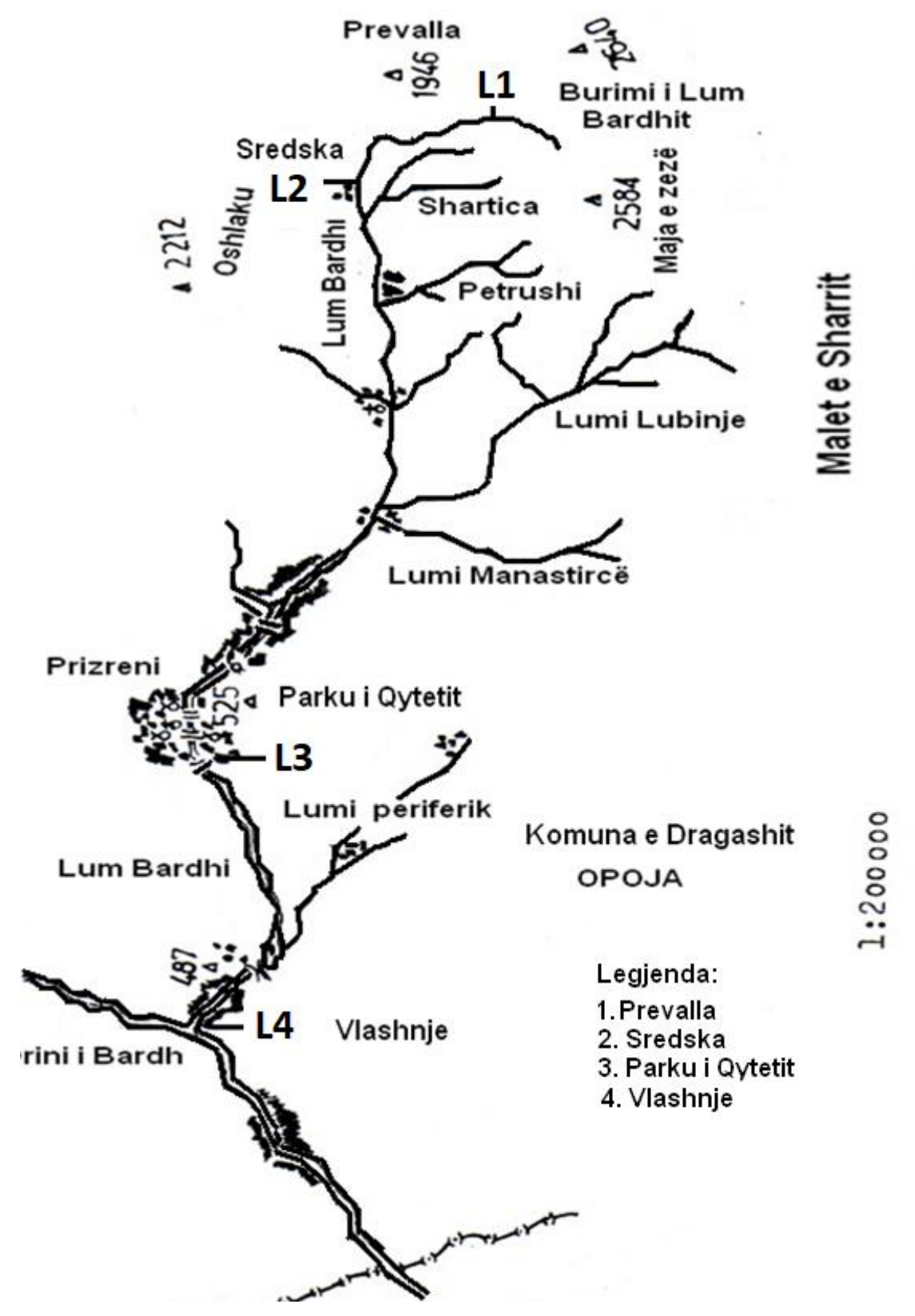

Figure 1. Map of sampling sites 


\section{Results and discussions}

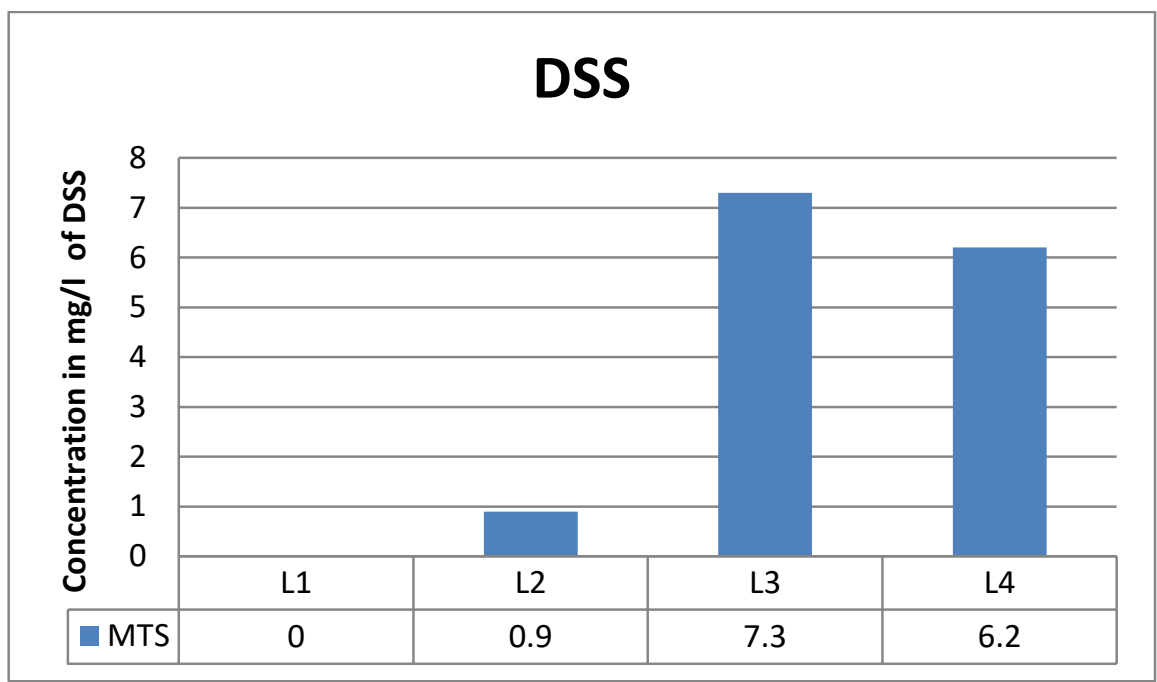

Figure 2. Graphic representation of DSS concentrations in the time interval May - June 2017

Referring to the data in Figure 2 it is noticed that besides the sources: L1 and L2, where the quality of the waters is good, in other monitoring sites this quality is of medium and low level. This is due to the pollution of water from various sources of pollutants during its flow. At the third place, it means in the City Park (L3) there is a huge increase in DSS which means that there is a serious pollution from urban liquid discharges while in Vlashnje (L4) we there is a decrease.

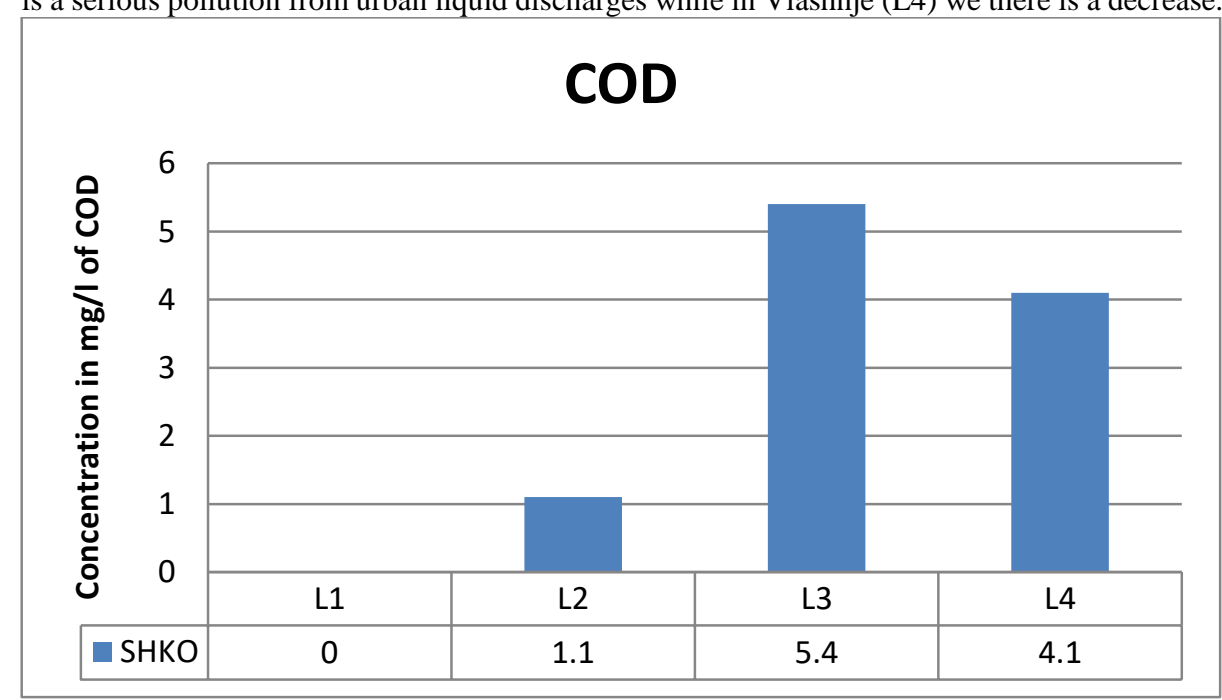

Figure 3. Graphic representation of COD concentrations in the time interval May - June 2017 
Referring to the COD indicators in Figure 3 it is noted that in the locations: L1 and L2, water quality is good, while in other monitoring sites water quality ranges from average to low. It is noted that the values of the COD indicator are increasing from the first place to the third place. At the third place, in the City Park (L3) there is a huge increase of COD, so, there is a serious pollution from the urban liquid discharges, household and in Vlashnje (L4), there's a decrease.

\section{BOD5}

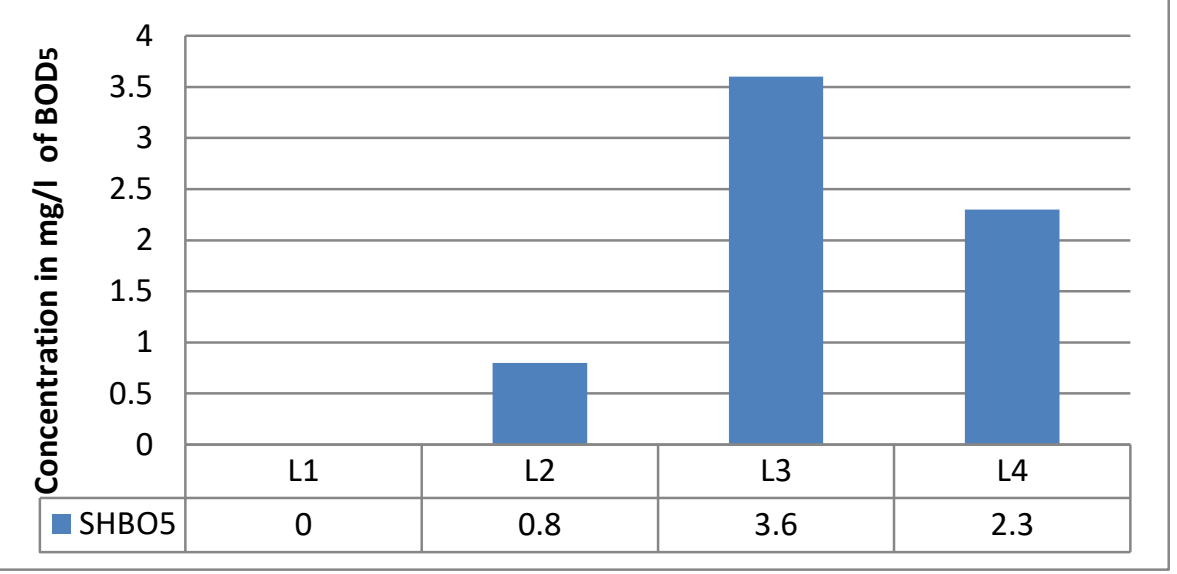

Figure 4. Graphic presentation of BOD5 concentrations (biochemical oxygen demand/consumption) in the time interval May - June 2017

Also referring to the data in Figure 4, it can be noted that, apart from sources: L1 and L2, compared to L3 and L4 source locations, where water quality is good, in other monitoring sites, this quality varies from average level values to the low ones. It is noted that the BOD5 indicator values are increasing from the first place to the third place. At the third place, in the City Park (L3) there is a large increase in BOD5 which means that there is a serious pollution from urban liquid discharges while in Vlashnje (L4) there's a decrease. 


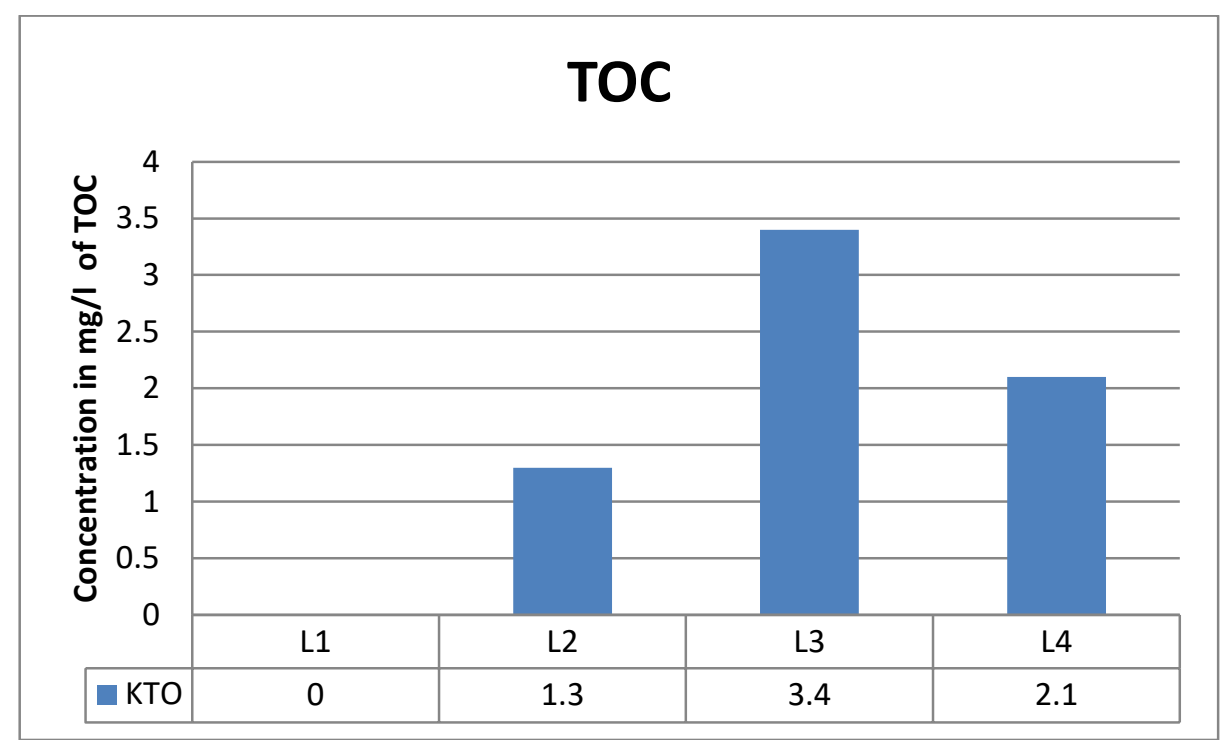

Figure 5. Graphic representation of TOC concentrations in the time interval May - June 2017

Referring to the data in figure 5, it is noted that for the sampling points: $\mathrm{L} 1$ and L2, compared to the water quality of the sampling point L2 and L3 of the source, water quality at the other monitoring sites is of the average level values, sometimes appears lower.

It is noted that the values of the TOC indicator are increasing from the first place to the third place. At the third place, in the City Park (L3) there is a large increase in TOC which means that there's a serious pollution from urban liquid discharges while in Vlashnje (L4) there's a decrease.

\section{Conclusions}

Based on the methodology of the study we think that we have managed to qualitatively and quantitatively quantify the pollution of the Lumbardhi River in four locations, in the period between May and June 2017. Results analysis show that the Lumbardhi River has no prior treatment.

$\downarrow$ During physical chemical quality analyzes of samples taken at the sites, there are variations of DSS, COD, BOD5 and TOC.

$\downarrow$ In the course of our study, we have managed to compare our results obtained from physical chemical quality analysis of water at the sites, which results that the values of the chemical parameters are greater at the third sampling place, in the City Park (L3) there is a huge increase of TOC, which means there's a serious pollution from urban liquid discharges.

Based on the data presented in this paper we can conclude that:

- Prizren still does not have for Lumbardhi: strategic water plan, water management plan, basin management plan and flood management plan.

- The water database is still incomplete and represents an obstacle to quality planning in the water sector;

- Unsustainable use of water resources and uncontrolled use of inert from river beds; 
- There is a lack of investment in the construction of sewage systems and wastewater treatment plants;

- There is a lack of scientific research in the field of water due to the absence of research institutes.

- Insufficient co-operation between the institutions responsible for the area of water,

- Insufficient co-operation between governmental, non-governmental and public institutions.

- There is no integrated monitoring system for surface and underground waters.

\section{References}

1. Stanely E. Manahan: Environmental Chemistry, Fourth Edition, Williard Grant Press, Boston (1984).

2. Shakya, Suman K.: "Alarming Trends of River Pollution in Kathmandu, Nepal", A Journal of the Environment, Volume 6, Number 7. (2001).

3. Abdullah S,: Conditioning ecological and zonal distribution of the Bistrica River makrozoobentosit in Prizren, page 2 - 5. Prizren (1979)

4. Alqi C,: Environmental Chemistry,page 127, 157- 158, 194 - 195. Tirana (2010)..

5. Anonym, Methods Standard ISO 9001: Hydrometeorology, Institute of Kosovo, page $3-7$, Pristina (2011)

6. Elmaz SH,: Chemical Technology and Environment, page 116, 334 - 335.Tirana , (2009)

7. Nexhat D: Environmental Chemistry, page 11 - 16. Prishtinë (1998)

8. Sabahidin V: Sanitary protection Lumbardhi bedding from sewage pollution. Project of the municipalityof Prizren, page 2- 4. Pristina (2011) 